\title{
Polyclonal B-cell lymphocytosis with binucleated lymphocytes (PPBL)
}

\author{
Xavier Troussard' \\ Edouard Cornet' \\ Jean-François Lesesve ${ }^{2}$ \\ Carine Kourel $^{3}$ \\ Hossein Mossafa ${ }^{3}$ \\ 'Laboratoire d'Hématologie Côte \\ de Nacre, Université Caen Basse \\ Normandie Caen, Registre Régional \\ des Hémopathies Malignes de Basse \\ Normandie, France; ${ }^{2}$ Laboratoire \\ d'Hématologie, Vandœuvre-Les-Nancy \\ Cedex, France; ${ }^{3}$ Département de \\ Génétique Humaine, Laboratoire \\ pasteur-Cerba, Cergy-Pontoise, \\ France \\ For the Groupe Français \\ d'Hématologie cellulaire (GFHC)
}

Correspondence: Xavier Troussard Laboratoire d'Hématologie, CHU Côte de Nacre, Boite Postale 95182, 14033

Caen Cedex 9, France

$\mathrm{Tel}+3323 \mathrm{I} 0650$ I4

Email troussard-x@chu-caen.fr

\begin{abstract}
Persistent polyclonal B-cell lymphocytosis (PPBL) is a rare and recently described entity. The review of the literature show PPBL is diagnosed predominantly but not exclusively in women, usually smokers. PPBL is recognized by a moderate, chronic and absolute lymphocytosis $\left(>4 \times 10^{9} / 1\right)$ in the peripheral blood. In $10 \%$ of cases without lymphocytosis, the PPBL diagnosis has to be suggested by peripheral blood examination showing in all cases atypical binucleated lymphocytes. A polyclonal serum IgM is also associated and HLA-DR7 expression is present in most cases. Contrary to B-cell chronic lymphoproliferative disorders (B-CLPD), peripheral $\mathrm{B}$ cells are polyclonal with kappa and lambda light-chain expression and no clonal rearrangement of immunoglobulin heavy chain genes is usually demonstrated. The detection of an extra isochromosome for the long arm of chromosome $3+\mathrm{i}(3)$ (q10) has to be considered as a specific marker of PPBL. We performed conventional cytogenetic analysis (CCA) in 111 patients with typical PPBL we followed-up more than 4 years. $+\mathrm{i}(3 \mathrm{q})$ was detected in $34 \%(33 / 98)$, PCC in $8 \%(8 / 98)$ and both abnormalities in $31 \%(30 / 98)$. CCA showed neither $+i(3 q)$ nor PCC in $28 \%$ (27/98). Fluorescence in situ hybridization (FISH) was also performed in 84 cases and $+\mathrm{i}(3 \mathrm{q})$ was detected in $71 \%(60 / 84)$. When combining both procedures in 84 patients, $+\mathrm{i}(3 \mathrm{q})$ was detected in 17 patients with negative CCA and was confirmed in 43 patients with positive CCA. CCA and FISH were both negative in 24 cases. Whether patients with PPBL are at increased risk of hematological malignancy remains unclear. After a median follow-up of 4.4 years, most PPBL patients presented a stable clinical and biological course. Six patients died from pulmonary cancer, myocardial infarction, cerebral aneurysm rupture or diffuse large B-cell lymphoma. Two patients had IgM monoclonal gammopathy of undetermined significance (MGUS) at the time of PPBL diagnosis and two other patients developed IgM MGUS respectively 12 and 22 years after PPBL diagnosis. A malignant non Hodgkin's lymphoma (NHL) appeared in 3 additional patients: two patients presented diffuse large B cell lymphoma and 1 patient a splenic marginal zone lymphoma. In conclusion, the possibility of PPBL to evolve toward a clonal proliferation, malignant lymphoma or secondary solid cancer lead us to consider PPBL not as a benign pathology. We recommend a careful and continued clinical and biological long-term follow-up in all PPBL patients.
\end{abstract}

Keywords: polyclonal lymphocytosis, binucleated lymphocytes, $+\mathrm{i}(3 \mathrm{q})$, premature chromosome condensation

\section{Introduction}

Benign or reactive lymphocytosis with an absolute lymphocyte count $>4 \times 10^{9} / 1$ is common in children and young adults and is usually related to infectious mononucleosis or other viral infections. In contrast, benign lymphocytosis in adults is unusual: transient absolute lymphocytosis has been described in "stress"-related emergency trauma and medical conditions but it lasts for only a few hours (Thomassen et al 1986). Persistent lymphocytosis is usually related to chronic lymphoproliferative disorders (CLPD), most commonly of B-cell origin (B-CLPD). A lymphocytosis in this age group indicates B-chronic lymphocytic leukemia (B-CLL), B-chronic prolymphocytic leukemia (B-PLL), hairy cell leukemia (HCL), Waldenström’s macroglobulinemia, 
follicular lymphoma with leukemic phase, splenic lymphoma with villous lymphocytes (SLVL), or intermediate lymphoma. These disorders are characterised by a chronic course, typical morphologic appearance of lymphocytes on peripheral blood smears, exclusively either kappa or lambda light-chain expression on B-cells surface, caryotypic abnormalities, and expansion of a clone of neoplastic lymphocytes. Conversely, polyclonal lymphocytosis can be observed in hyposplenic states (Wilkinson et al 1983), in nodular lymphocyte predominant Hodgkin's disease (Mariette et al 1993), in rheumatoid polyarthritis (Plater-Zirberck et al 1985) and in other medical conditions such as Gaucher disease (Marty et al 1988).

Gordon and colleagues (1982) described a syndrome associating chronic absolute lymphocytosis, polyclonal B-cell lymphocytosis with binucleated lymphocytes (PPBL) in the peripheral blood and a polyclonal increase of serum IgM in three women, all of whom expressed the HLA-DR7 antigen. We subsequently described cytogenetic abnormalities in seven patients with PPBL, including an additional isochromosome for the long arm of chromosome $3+\mathrm{i}(3 \mathrm{q})$ in 6 cases and premature chromosome condensation (PCC) in all 7 cases (Troussard et al 1994). That cytogenetic profile was subsequently confirmed in a large number of case reports.

The real incidence of PPBL has never been calculated because PPBL is probably underdiagnosed, as most patients are asymptomatic. Nevertheless PPBL appears to be a rare haematological disorder and underreported (Delannoy et al 1993; Agrawal et al 1994; Mossafa et al 1999). In this review, we focus our interest on the clinical, morphologic, immunologic and karyotypic findings in patients with PPBL. We had the opportunity to collect the clinical data and the specimens of a very large cohort of 111 patients with typical PPBL in France. We will present the specific clinical and biological data in that very large cohort and also discuss the aetiology of PPBL.

The identification of PPBL is important to distinguish PPBL from others B-CLPD. Whether this syndrome represents a premalignant (Casassus et al 1987) or benign disease remains unclear. Although long-term follow-up suggests that whenever malignant progression occurs, it is after a long latency. The benign clinical course and lack of biological evolution in the majority of PPBL cases suggest that the recognition is so important that aggressive therapy could be avoided.

\section{Clinical data}

PPBL affects mainly adults but it was reported in a 3-month-old baby (Gomez et al 2000). The median age is approximately
40-50 years. Most patients are asymptomatic: the presence of splenomegaly is observed in $10 \%$ of cases and only a very few patients had hepatomegaly or adenopathy based on clinical examination and/or thoracic and abdominal computerised tomography. Antiphospholipid/cofactor antibodies of immunoglobulin (IgM) isotype or lupus anticoagulant was also reported in a few cases (Granel et al 2002).

The majority of PPBL patients present with an absolute and moderate lymphocytosis $>4 \times 10^{9} / \mathrm{L}$. In $10 \%$ of patients without absolute lymphocytosis, PPBL diagnosis has to be suggested by cytology and confirmed by detection of typical binucleated lymphoid cells and $+\mathrm{i}(3 \mathrm{q})$. Neutrophil and platelet counts are usually normal. Analysis of serum immunoglobulin reveal persistent, stable and polyclonal increase of IgM levels, with low to normal levels of IgA and IgG. No increase incidence of infection or any clinical evidence of defective humoral immunity was notified. Ninety percent of PPBL patients are HLA-DR7-positive (Troussard et al 1996) but no patient complained adult coeliac disease.

\section{Cytology: presence of binucleated lymphocytes in the peripheral blood}

Binucleated lymphocytes are detected in the peripheral blood of all PPBL patients. The majority of lymphocytes are large with abundant faintly, basophilic cytoplasm and in all patients a characteristic nuclei demonstrating a rounded or more commonly irregular form with variable numbers of binucleated cells (Figure 1). Nuclei range from those demonstrating a slight indentation to bilobed forms with the inconstant presence of an internuclear linkage in a few cells. Nuclear chromatin is dense and nucleoli usually visible. Binucleated lymphocytes are not specific of PPBL and have been described after irradiation (Roy-Taranger et al 1965) and more rarely in B-CLPD, as HCL Japanese variant (Troussard et al 1997), B-CLL or marginal zone B-cell lymphoma (Samson et al 2002).

The investigation of bone marrow biopsies is limited in PPBL. The bone marrow is infiltrated by a slight or moderate intravascular and at a lesser extent interstitial lymphocytic pattern (Feugier et al 2004).

\section{Immunophenotyping: a polyclonal expansion of memory B-cells}

The lymphocytosis is clearly of the B-cell type. Lymphocytes react with the CD19, CD20 and CD22 antigens. Both kappa and lambda light-chain are expressed, indicating a polyclonal expansion of the B-lymphocyte pool (Troussard et al 1994; 

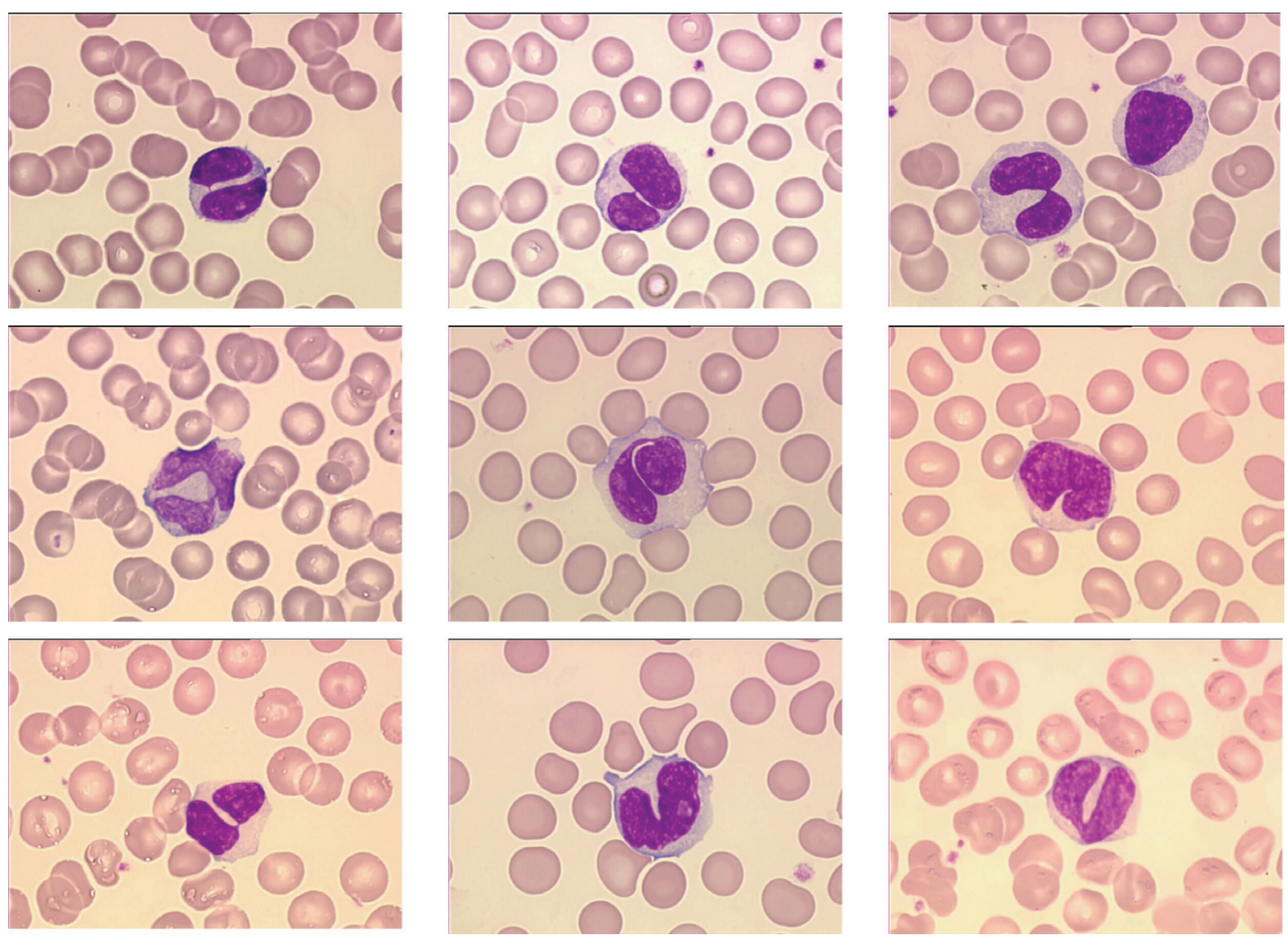

Figure I Morphologic features showing typical binucleated cells in a PPBL patient.

Mossafa et al 1996). Double labeling performed on cytocentrifuge slides with kappa and lambda monoclonal antibodies by immunoenzymatic methods using $\mathrm{ABC}$ (avidin biotin peroxydase complex) and APAAP (alkaline phosphatase antialkaline phosphatase) procedures showed both kappa and lambda lightchain in binucleated lymphocytes and nonbinucleated lymphoid cells (Troussard et al 1994). When using cytofluorometry, the cellular DNA content determination and proliferation index analysis is not different from that of the controls and diploidy can be demonstrated in binucleated lymphocytes by image analysis and manual cell sorting.

Peripheral B cells co-express $\operatorname{IgM}$ and $\operatorname{IgD}$, suggesting that they derive from a naive B-cell subset (Himmelmann et al 2001; Loembé et al 2002). CD27 is a type I glycoprotein expressed on some B cells and the majority of T cells, and is a member of the tumor necrosis factor (TNF) receptor family, with unique cysteine-rich motifs. $\mathrm{CD} 27^{+} \mathrm{B}$ cells exhibit several features of primed (memory) B cells. In five PPBL patients, a large increase in the number of $\mathrm{IgD}+, \mathrm{CD} 27+$ double positive $\mathrm{B}$ cells, $(60 \%-88 \%$ versus $8 \%-15 \%$ in the controls) was detected in the peripheral blood. The number of $\mathrm{CD} 27+$ which also coexpress receptor-type protein tyrosine phosphatase CD148 (CD27+ CD148+ double-positive B cells) was also increased
(Himmelmann et al 2001). PPBL B cells express CD25 and CD23 with usually no or low CD5 antigens (Salcedo et al 2002). An unusual CD5 positive phenotype can be observed (Reeder et al 1999). The cells also express CD24, CD79, FMC7, and CD21 at levels higher than normal B lymphocytes. Taken together, all those data suggest B-cell population is a memory B-cell population distinguished by the expression of CD27, IgM ${ }^{\text {high }}, \mathrm{CD} 21^{\text {high }}, \mathrm{CD}^{\text {low }}$, and $\mathrm{CD} 23^{\text {low }}$, a profile associated with a normal marginal B-cell compartment (Salcedo et al 2002).

An associated abnormality of $T$ cells has not been found: not only was the absolute number of T-cells normal but the CD4 and CD8 cells subsets were quantitatively normal as well.

\section{Chromosome analysis in PPBL patients: an unique cytogenetic profile associating $\mathbf{i}(3 q)$ and premature chromosome condensation}

Following stimulation of peripheral blood lymphocytes with pokeweed, the presence of an extra chromosome 3 long arm $\mathrm{i}(3 \mathrm{q})$ was identified for the first time in 1989. $+\mathrm{i}(3)(\mathrm{q} 10)$ was present in $3 / 26$ metaphases in only $1 / 6$ patients with 
PPBL (Perreault et al 1989). However, when using the combinations of the tetrad-canoyl-o-phorbol 13 acetate (TPA) and lipopolysaccharide (LPS) from Escherichia coli used in some samples, which encourages B lymphoid proliferation, $+\mathrm{i}(3 \mathrm{q})$ (Figure 2 ) was detected more frequently and was observed in 6/7 PPBL patients (Mossafa et al 1996). $+\mathrm{i}(3 \mathrm{q})$ is distributed and restricted in nonbinucleated B cells whatever the light chain expression (Troussard et al 1999). In B-CLPD, distinct, recurring and highly consistent chromosomal changes are observed: however $+\mathrm{i}(3 \mathrm{q})(\mathrm{q} 10)$ is rarely identified and to our knowledge was detected in only one case of Waldenstrom macroglobulinemia (Wong et al 2002) and in a few cases of chronic lymphocytic leukemia (Specchia et al 2002; Wong et al 2002). G1 premature chromosome condensation (PCC) (Figure 3) is also a characteristic of PPBL patients. PCC, originally described in virally infected cells, is also detected in normal cells treated with mould extract, cytochalasin B. The common feature is the presence of asynchronous mitosis in multinucleated cells. One nucleus must be in metaphase and its presence results in the condensation of the chromatin of an adjacent interphase nucleus. The morphology depends on the interphase cells. In PPBL, the morphology of the PCC indicate condensation of G1 and G2 cells, exhibiting single and double chromatids, respectively. PCC of S-phase cells is not observed in any case. Interestingly PCC can be associated with $+\mathrm{i}(3 \mathrm{q})$. As both abnormalities, either $+\mathrm{i}(3 \mathrm{q})$ or $\mathrm{PCC}$, are rarely present in other benign or malignant proliferations, a strong correlation between PPBL and $\mathrm{i}(3 \mathrm{q})$ and/or PCC is probable.

In a large series of 111 patients with PPBL we follow-up, conventional cytogenetic analysis (CCA) allowed us to identify extra isochromosome $+\mathrm{i}(3)(\mathrm{q} 10)$ in $34 \%(33 / 98)$, PCC in $8 \%(8 / 98)$ and both abnormalities in 31\% (30/98). CCA showed neither $+\mathrm{i}(3)(\mathrm{q} 10)$ nor PCC in $28 \%(27 / 98)$. Isochromosome $+\mathrm{i}(3 \mathrm{q})$ was also studied in interphase with

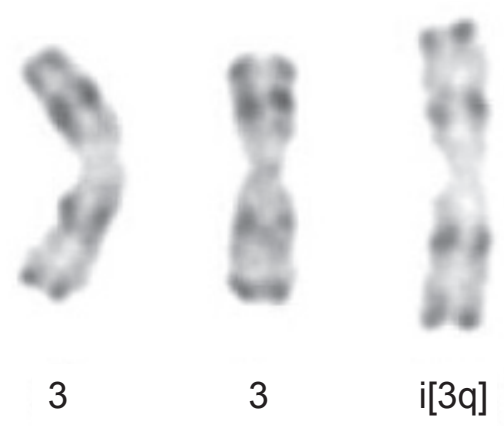

Figure 2 Partial karyotype showing $+i(3 q)$ - $R$-banding from patient with persistent polyclonal B-cell lymphocytosis. alpha-satellite chromosome 3 specific (SO CEP3) and LSI 3'BCL6 (3q27) break apart probes obtained from Abott Molecular (Rungis, France) and was detected in 71\% (60/84). We also combined CCA and FISH analysis in 84 patients: after $\mathrm{FISH},+\mathrm{i}(3 \mathrm{q})$ was detected in 17 patients with negative CCA and was confirmed in 43 patients with positive CCA. CCA and FISH were both negative in 24 cases.

Trisomy 3 can be detected in addition to extra $+\mathrm{i}(3)(\mathrm{q} 10)$, suggesting that PPBL is associated with an increase frequency of chromosome 3 instability (Callet-Bauchu et al 1999). When excluding $+\mathrm{i}(3)(q 10)$ and PCC, chromosomal instability is also a common occurrence in PPBL and is observed in more than two thirds of PPBL patients. It is characterised by the presence of others independent clonal abnormalities, $\operatorname{del}(6 q),+\operatorname{der}(8)$ or +8 , poliploid karyotype, structural changes, aneuploidy and/or non clonal chromosomal aberrations with either loss or more frequently gain of chromosomes (Mossafa et al 2004).

The long-term follow-up of PPBL remains to be determined and the role of $\mathrm{i}(3 \mathrm{q})$ in the pathogenesis of PPBL is debatable. The gain of chromosome $3 \mathrm{q}$ was demonstrated as a pivotal genetic aberration transition from severe dysplasia/carcinoma in situ to invasive cervical carcinoma of the uterine cervix (Heselmeyer et al 1996). It could have a role in the possibility of emergence of a clonal and/or malignant subpopulation. On the other hand, isochromosome, i(3)(q10) inhibits muscle differentiation, when transferred into myoblasts. The $\mathrm{i}(3 \mathrm{q})$ is in that model able to induce an abnormal phenotype of the cells including abnormal centrosome amplification, aneuploidy and loss of G1 arrest following $\gamma$-irradiation (Smith et al 1998).

\section{Molecular studies}

To determine if the lymphocytosis observed in PPBL patients represented a clonal, biclonal, polyclonal or random expansion of cells, immunoglobulin gene rearrangements were examined. In almost all cases, molecular studies show a polyclonal pattern. Southern hybridization of DNA with immunoglobulin probes was performed in 14 patients and failed to show any clonal population in 12 patients; however two patients curiously showed an immunoglobulin gene rearrangement (Chan et al 1990; Delage et al 1992). Polymerase chain reaction (PCR) procedures using either consensus primers for the FR3 portion of the variable region and/or VH family specific primers for the FR1 region $(12,16)$ show also a polyclonal expansion of B cells.

The study of Ig-V gene somatic mutations was rarely performed in the B cells isolated from PPBL patients 

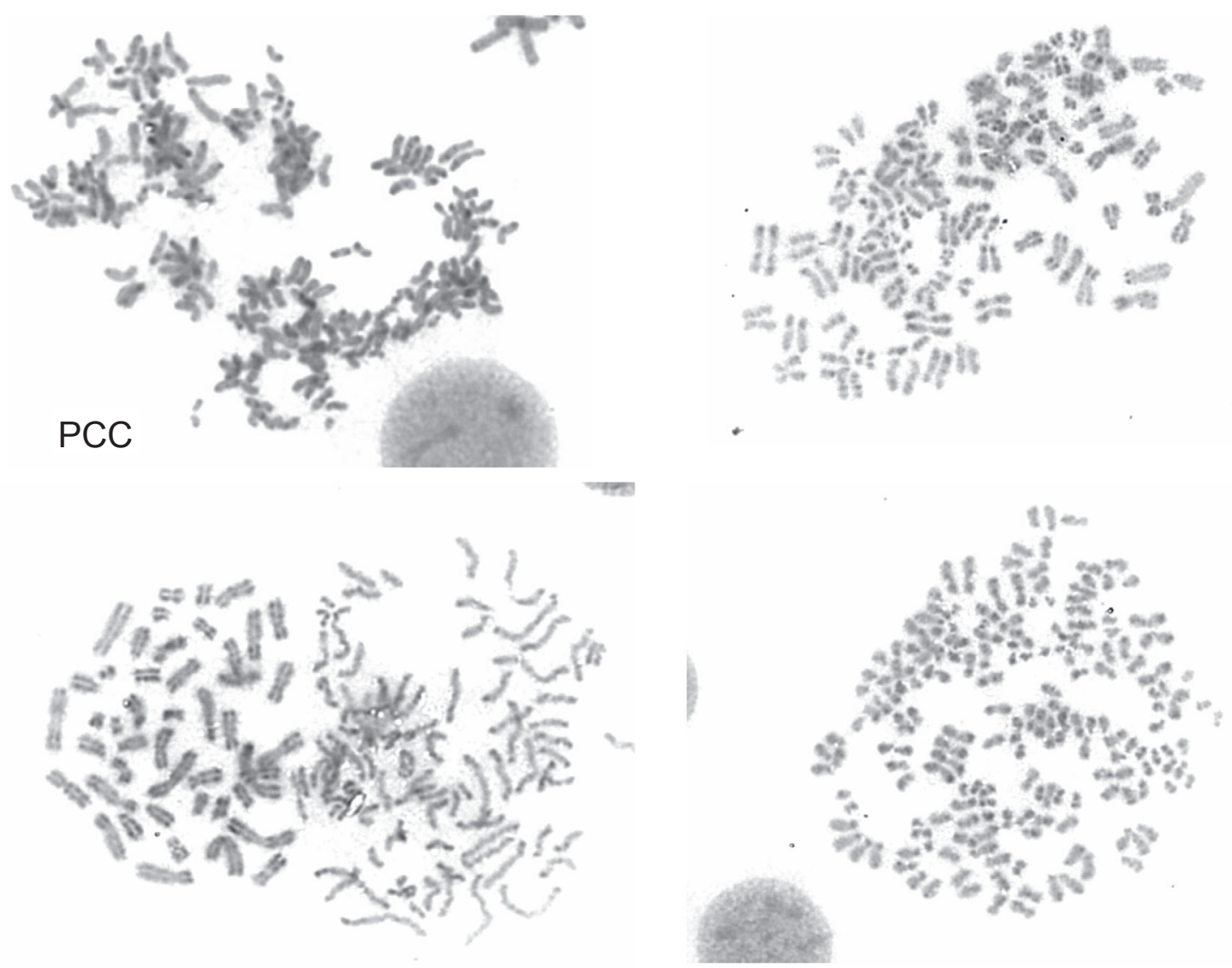

Figure 3 Premature chromosome condensation (PCC) R-banding of an early GI-PCC with condensed single chromatide.

(Loembé et al 2002; Salcedo et al 2002). However, the relevant marker of memory B cells thus far identified is the presence of somatically mutated high-affinity antigen receptors. When combining both studies, 90 clones were analysed from 6 PPBL patients and $85.5 \%$ clones (77/90) were mutated, a proportion of sequences higher than that reported for normal blood lymphocytes. Mutations in PPBL cells are present in all three framework regions (FR) as well as CDR1 and CDR2 but the number of observed $\mathrm{R}$ mutations is usually lower than that expected for FR but higher than expected for CDR, suggesting no evidence of positive antigenic selection following somatic hypermutation.

Using nested PCR assay, $B C L-2 / I g H$ rearrangements are identified in PPBL patients (Delage et al 1997, 1998, 2001; Granados et al 1998). We also studied the presence of BCL-2/ $\mathrm{IgH}$ rearrangements in a series of eight PPBL patients and demonstrated the constant presence of $B C L-2 / \mathrm{IgH}$ rearrangements in $8 / 8$ DNA samples, multiple rearrangements in $3 / 8$ cases and also normal BCL-2 protein expression, as compared to BCL-2 level in B lymphocytes from healthy population (Lancry et al 2001). When pooling all the published results, $B C L-2 / I g H$ rearrangements are detected both in the major breakpoint region (MBR) and the minor cluster region (mcr). When using a quantitative real-time PCR, Himmelmann and colleagues (2001) demonstrated the presence in the peripheral blood of a high number of 1055-3487 $\mathrm{t}(14$; 18)-positive cells per $10^{6} \mathrm{~B}$ cells, as compared to only nine positive cells in $10^{6} \mathrm{~B}$ cells obtained from a buffy coat from a healthy donor. $B C L-2 / I g H$ rearrangements were also identified in nearly $50 \%$ of normal individuals: the frequency of translocations increases with age and heavy smoking. In those cases, the frequency of the $B C L-2 / I g H$ rearrangements is estimated to be equal or less than one in $10^{5}$ to $10^{6} \mathrm{~B}$ cells. Despite the presence of $B C L-2 /$ $\mathrm{IgH}$ rearrangements, the accumulation of B lymphocytes in PPBL is probably not related to an overexpression of BCL-2 protein (Himmelmann et al 2001; Lancry et al 2001).

\section{Functional defect in PPBL: conflicting signals from the CD40 survival and Fas death pathways}

The accumulation of polyclonal binucleated mature B lymphocytes in the peripheral blood could be explained by defects in apoptosis and/or uncontrolled cell growth. 
Overexpression of the antiapoptotic protein Bcl-2 in CLL is associated with an aggressive clinical course, chemotherapy resistance and shortened survival. In PPBL, Bcl-2 is equivalent to that detected in lymphocytes of healthy individuals (Lancry et al 2001). The polyclonal B-cells are resistant to Fas stimulation despite a high expression of Fas receptor and apoptosis is induced after etoposide treatment (Roussel et al 2003). In contrast to normal B cells, defects of the CD40 survival pathway has been described in PPBL patients (Loembé et al 2001). B-cell accumulation observed in PPBL could result from conflicting signals from the CD40 survival and Fas death pathways.

\section{PPBL requires a careful a long-term follow-up}

Whether patients with PPBL are at increased risk of hematologic malignancy remains unclear (Troussard et al 1999). One patient developed a malignant pulmonary blastoma 20 years after PPBL was diagnosed (Lawlor et al 1991). One additional PPBL patient developed B large cell lymphoma 19 years after PPBL diagnosis (Roy et al 1998). After a median follow-up of 4.4 years (0.5-29 years), PPBL patients presented a stable clinical and biological course in 99/111 cases (89\%). In two patients, we noticed a decrease of lymphocytosis and the number of binucleated lymphocytes but isochromosome $+\mathrm{i}(3 \mathrm{q})$ persisted 2 years after stopping tobacco. Six patients died: one heavy smoker patient from pulmonary cancer nine years after PPBL diagnosis, 1 from myocardial infarction, 1 from cerebral aneurysm rupture, 2 deaths from unknown causes and 1 from diffuse large B-cell lymphoma described later. Two patients had IgM monoclonal gammopathy of undetermined significance (MGUS) at the time of PPBL diagnosis. Two other patients developed IgM MGUS (serum IgM, $6.9 \mathrm{~g} / \mathrm{L}$ and $12.88 \mathrm{~g} / \mathrm{L}$ ) 12 and 22 years after PPBL diagnosis, respectively. In those 4 cases, no bone marrow biopsy was performed. IgM gammopathy remained asymptomatic and stable after a median followup of 102 months (range 52-348). Two patients presented pulmonary cancer in the clinical course of PPBL and one patient developed cervical cancer 12 years after diagnosis of PPBL. A malignant non-Hodgkin's lymphoma (NHL) was also observed in 3 additional patients: two patients presented diffuse large B cell lymphoma (DLBCL) and 1 patient a splenic marginal zone lymphoma (SMZL). It therefore appears that, while the majority of patients demonstrate a polyclonal B lymphocytosis based on immunological and genotypic analysis, the emergence of a clonal sub-population is possible (Cornet et al 2008).

\section{Etiology of PPBL}

The aetiology of polyclonal B-cell lymphocytosis remains elusive. An association with cigarette smoking was suggested by Carstairs and colleagues (1985). These authors described four patients with PPBL, all cigarette smokers, in one of whom the lymphocyte count and morphology were abnormal when she smoked and not when she abstained. However, the role and influence of environmental factors and particularly tobacco is debatable, as we observed one female patient who had never smoke and we were unable to detect binucleated lymphocytes on cytocentrifuge slides in 30 asymptomatic female heavy smokers. Lymphocyte binuclearity is not observed in normal individuals and has been described only after low-dose irradiation (Roy-Taranger et al 1965).

The binucleated morphology of lymphocytes could suggest an association with persistent viral infection such as Epstein-Barr virus (EBV) (Mittereer et al 1995). EBV is responsible for a polyclonal lymphoproliferative process in patients with immune deficiency. Chow and colleagues (1992) demonstrated the presence of EBV in the peripheral blood lymphocytes (but not in binucleated lymphocytes) from one patient by in situ hybridization and PCR. These studies are insufficient to exclude and/or confirm the role of EBV in PPBL.

The association with HLA-DR-7 phenotype suggests a possible genetic disorder. Taken together with the presence of chararacteristic, binucleated lymphocytes in asymptomatic family members, we suggest a genetic predisposition as a more likely possibility. The description of PPBL in identical twins (Carr et al 1997) and also in a family including PPBL in a brother and sister (Himmelmann et al 2001) strengthens that hypothesis as well as the detection of multiple $B C L-2 /$ $\mathrm{IgH}$ rearrangements in $8 / 10$ individuals among first-degree relatives (Delage et al 2001).

\section{Conclusion}

PPBL is characterised by persistent and stable lymphocytosis (in but not exclusively female patients) with binucleated lymphocytes on peripheral blood smears and a polyclonal increase of serum IgM. Immunophenotyping revealed in all cases a polyclonal expansion of B-lymphocytes. Whether this syndrome represents a premalignant disease process or an actual polyclonal lymphocytosis remains unsettled. The occasional reports of clonal Ig rearrangements in this disorder suggest that in a minority of cases the polyclonal expansion may be followed by the emergence of one predominant clone. The demonstration of clinically, benign, clonal lymphoid population is well recognized in several $\mathrm{T}$ cell disorders such 
as large granular lymphocytes expansion. The benign clinical course and the lack of biological evolution in the majority of cases suggest that the importance in recognition of this disorder lies in the avoidance of aggressive therapy for these cases. A careful follow-up of these patients is mandatory: prospective immunological and genetic studies performed at different stages of the disease may clarify this issue.

\section{Disclosure}

The authors report no conflicts of interest in this work.

\section{References}

Agrawal S, Matutes E, Voke J, et al. 1994. Persistent polyclonal B-cell lymphocytosis. Leuk Res, 18:791-5.

Callet-Bauchu E, Gazzo S, Poncet C, et al. 1999. Distinct chromosome 3 abnormalities in persistent polyclonal B-cell lymphocytosis. Genes Chromosomes Cancer, 26:221-8.

Carr R, Fishlock K, Matutes E. 1997. Persistent polyclonal B-cell lymphocytosis in identical twins. Br J Haematol, 96:272-4.

Carstairs KC, Francombe WH, Scott JG, et al. 1985. Polyclonal lymphocytosis of B-lymphocytes induced by cigarette smoking? Lancet, 11:1094.

Cassasus P, Lortholary P, Komarover H, et al. 1987. Cigarette smoking related to persistent polyclonal B-lymphocytis: a premalignant state. Arch Pathol Lab Med, 111:1081.

Chan MA, Benedict SH, Carstairs KC, et al. 1990. Expansion of B-lymphocytes with an unusual immunoglobulin rearrangment associated with atypical lymphocytosis and cigarette smoking. Am J Respir Cell Mol Biol, 2:549-52.

Chow KC, Nacilla JQ, Witzig TE, et al. 1992. Is persistent polyclonal B lymphocytosis caused by Epstein-Barr virus? A study with polymerase chain reaction and in situ hybridization. Am J Hematol, 41:270-5.

Cornet E, Lesesve JF, Mossafa H, et al; the Groupe Français d'Hématologie Cellulaire (GFHC). 2008. Long-term follow-up of 111 patients with persistent polyclonal b-cell lymphocytosis ( $\mathrm{ppbl}$ ) with binucleated lymphocytes. Leukemia, In press.

Delage B, Darveau A, Jacques L, et al. 1992. Chronic B-cell lymphocytosis of the young woman: clinical, phenotypic, and molecular studies. Blood, 80(Suppl 1):447a.

Delage R, Jacques L, Massinga-Loembe M, et al. 2001. Persitent polyclonal B-cell lymphocytosis: further evidence for a genetic disorder associated with B-cell abnormalities. Br J Haematol, 114:666-70.

Delage R, Roy J, Jacques 1, et al. 1997. Multiple bcl2/Ig gene rearrangements in persistent polyclonal lymphocytosis. Br J Haematol, 97:589-95.

Delage R, Roy J, Jacques L, et al. 1998. All patients with persistent polyclonal B cell lymphocytosis present $\mathrm{Bcl}-2 / \mathrm{Ig}$ gene rearrangements. Leuk Lymphoma, 31:567-74.

Delannmoy C, Dijan D, Wallef G, et al. 1993. Cigarette smoking and chronic polyclonal B-cell lymphocytosis. Nouv Rev Fr Hématol, 35:141-4.

Feugier P, De March AK, Lesesve JF, et al. 2004. Intravascular bone marrow accumulation in persistent polyclonal lymphocytosis: a misleading feature for B-cell neoplasm. Mod Pathol, 17:1087-96.

Gomez P, Matutes E, Sanchez J, et al. 2000. An unusual form of persistent polyclonal B lymphocytosis in an infant. Br J Haematol, 110:430-3.

Gordon DS, Jones BM, Browing SW, et al. 1982. Persistent polyclonal lymphocytosis of B-lymphocytes. N Engl J Med, 307:232-6.

Granados E, Llamas P, Pinilla I, et al. 1998. Persistent polyclonal B lymphocytosis with multiple bcl-2/IgH rearrangement: a benign disorder. Haematologica, 83:369-75.

Granel B, Serratrice J, Disdier P, et al. 2002. Anti-phospholipid/cofactor antibodies in three cases of persistent polyclonal B lymphocytosis. Br J Haematol, 119:875-6.
Heselmeyer K, Schrock E, du Manoir S, et al. 1996. Gain of chromosome $3 q$ defines the transition from severe dysplasia to invasive carcinoma of the uterine cervix. Proc Natl Acad Sci U S A, 93:479-84.

Himmelmann A, Gautschi O, Nawrath M, et al. 2001. Persistent polyclonal B-cell lymphocytosis is an expansion of functional IgD+ CD27+ memory B-cells. Br J Haematol, 114:400-5.

Himmelmann A, Rüegg R, Fehr J. 2001. Familial persistent polyclonal B cell lymphocytosis. Leuk Lymphoma, 41:157-60.

Lancry L, Roulland S, Roué G, et al. 2001. No bcl-2 protein over expression but bcl-2/IgH rearrangements in B cells of patients with persistent polyclonal B-cell lymphocytosis. Hematol J, 2:228-33.

Larcher C, Fend F, Mitterer M, et al. 1995. Role of Epstein-Barr virus and soluble CD21 in persistent polyclonal B-cell lymphocytosis. $\mathrm{Br} J$ Haematol, 90:532-40.

Lawlor E, Murray M, O’Brian DS, et al. 1991. Persistent polyclonal B lymphocytosis with Epstein-Barr virus antibodies and subsequent malignant pulmonary blastoma. J Clin Pathol, 44:341-2.

Loembe MM, Lamoureux J, Deslauriers N, et al. 2001. Lack of CD40dependent B-cell proliferation in B lymphocytes from patients with persistent polyclonal B-cell lymphocytosis. $\mathrm{Br} J$ Haematol, 113:699-705.

Loembe MM, Néron S, Delage R, et al. 2002. Analysis of expressed VH genes in persistent polyclonal B cell lymphocytosis reveals absence of selection in CD27 + IgM + IGD + memory B cells. Eur J Immunol, 32:3678-88.

Mariette X, Tsapis A, Oksenhendler E, et al. 1993. Nodular lymphocyte predominance Hodgkin's disease featuring blood atypical polyclonal B-cell lymphocytosis. Br J Haematol, 85:813-5.

Marty GE, Ryan ET, Papadopoulos NM, et al. 1988. Polyclonal B-cell lymphocytosis and hypergammaglobulinemia in patients with Gaucher disease. Am J Haematol, 29:189-94.

Mitterer M, Pescosta N, Fend F, et al. 1995. Chronic active Epstein-Barr virus disease in a case of persistent polyclonal B-cell lymphocytosis. Br J Haematol, 90:526-31.

Mossafa H, Malaure H, Maynadie M, et al; for the Groupe Française d'Hématologie Cellulaire (GFHC). 1999. Persistent polyclonal B lymphocytosis with binucleated lymphocytes: a study of 25 cases. Br J Haematol, 104:486-93.

Mossafa H, Tapia S, Flandrin G, et al; for the Groupe Français d'hématologie Cellulaire (GFHC). 2004. Chromosomal instability and ATR amplification gene in patients with persistent polyclonal B-cell lymphocytosis (PPBL). Leuk Lymphoma, 45:1401-6.

Mossafa H, Troussard X, Valensi F, et al. 1996. Isochromosome i(3q) and premature chromosome condensation are recurrent findings in chronic B-cell lymphocytosis with binucleated lymphocytes. Leuk Lymphoma, 20:267-73.

Perrault C, Boileau J, Gyger M, et al. 1989. Chronic B-cell lymphocytosis. Eur J Haematol, 2:361-7.

Plater-Zyberk C, Maini RN, Lam K, et al. 1985 A rheumatoid arthritis B cell subset expresses a phenotype similar to that in chronic lymphocytic leukemia. Arthritis Rheum, 28:971-6.

Reeder CB, Conley CR. 1999. CD5+ persistent polyclonal B-cell lymphocytosis in a male. Leuk Lymphoma, 33:593-6.

Roussel M, Roué G, Sola B, et al. 2003. Dysfunction of the Fas apoptotic signaling pathway in persistent polyclonal B-cell lymphocytosis. Haematologica, 88:239-40.

Roy J, Ryckman C, Bernier V, et al. 1998. Large cell lymphoma complicating persistent polyclonal B cell lymphocytosis. Leukemia, 12:1026-30.

Roy-Taranger M, Mayaud G, Davydoff-Alibert S. 1965. Binuclear lymphocytes in the blood of individuals irradiated by a low dose. Rev Fr Etud Clin Biol, 10:958-65.

Salcedo I, Campos-Caro A, Sampalo A, et al. 2002. Persistent polyclonal B lymphocytosis: an expansion of cells showing IgVH gene mutations and phenotypic features of normal lymphocytes from the CD27+ marginal zone B-cell compartment. Br J Haematol, 116:662-6. 
Samson T, Mossafa H, Lusina D, et al. 2002. Dicentric chormosome 3 associated with binucleated lymphocytes in atypical B-cell chronic lymphoproliferative disorder. Leuk Lymphoma, 43:1749-54.

Smith L, Liu SJ, Goodrich L, et al. 1998. Duplication of ATR inhibits MyoD, induces aneuploidy and eliminates radiation-induced G1 arrest. Nat Genet, 19:39-46.

Specchia G, Albano F, Anelli L, et al. 2002. Concomitant tetrasomy 3q and trisomy 18 in CD5-, CD13+ chronic lymphocytic leukemia. Cancer Genet Cytogenenet, 133:160-3.

Thomassen HV, Boyko WJ, Montaner JS, et al. 1986. Absolute lymphocytosis associated with nonsurgical trauma. Am J Clin Pathol, $86: 480-3$.

Troussard X, Flandrin G. 1996. Chronic B-cell lymphocytosis with binucleated lymphocytes (LWBL): a review of 38 cases. Leuk Lymphoma, 20:275-9.
Troussard X, Mossafa H, Flandrin G. 1997. Identity between hairy B-cell lymphoproliferative disorder and persistent polyclonal B lymphocytosis? Blood, 90:2110-1.

Troussard X, Mossafa H, Salaün V. 1999. Persistent polyclonal lymphocytosis. Leukemia, 13:497-8.

Troussard X, Valensi F, Debert C, et al. 1994. Polyclonal lymphocytosis with binucleated lymphocytes: a genetic predisposition. Br J Haematol, 88:275-80.

Wilkinson LS, Tang A, Gjedsteda A. 1983. Marked lymphocytosis suggesting chronic lymphocytic leukemia in three patients with hyposplenism. Am J Med, 75:1053-6.

Wong KF, So CC, Chan JCW, et al. 2002. Gain of chromosome 3/3q in B-cell chronic lymphoproliferative disorder is associated with plasmacytoid differentiation with or without IgM overproduction. Cancer Genet Cytogenet, 136:82-5. 